\title{
AN UNUSUAL CLINICAL PRESENTATION OF SUBACUTE THYROIDITIS IN A PATIENT WITH HASHIMOTO THYROIDITIS
}

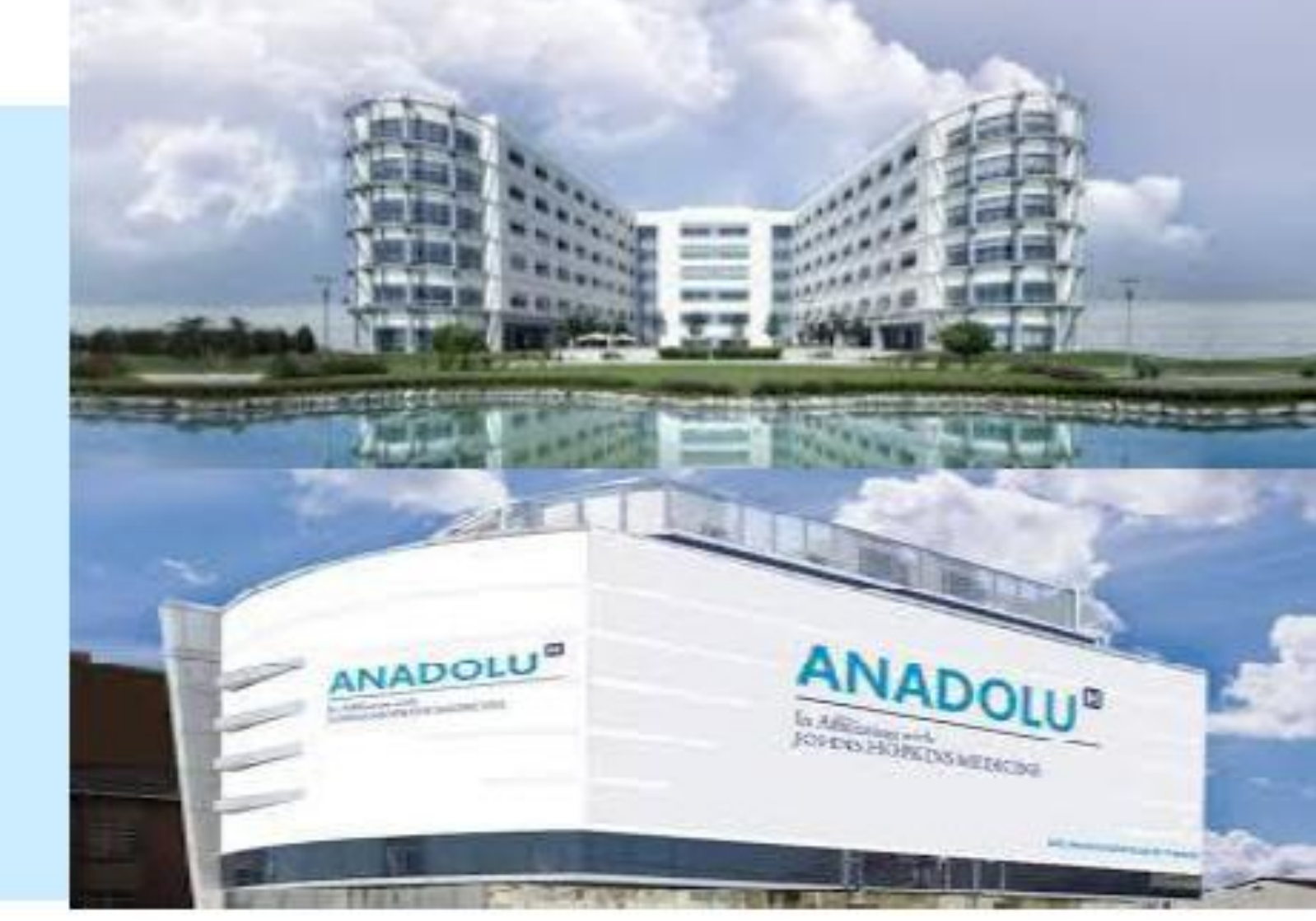

\section{A. Serap Yalin ${ }^{1}$, Erdem Turemen ${ }^{1}$, Mithat Biyikli', Omer Aydıner², Ozgur Sarıca², Saime Ramadan ${ }^{3}$, Kezban Berberoglu ${ }^{4}$}

ANADOLU MEDICAL CENTER, DEPARTMENT OF ENDOCRINOLOGY AND METABOLISM ${ }^{1}$, ANADOLU MEDICAL CENTER, DEPARTMENT OF RADIOLOGY ${ }^{2}$, ANADOLU MEDICAL CENTER, DEPARTMENT OF PATHOLOGY ${ }^{3}$, ANADOLU MEDICAL CENTER, DEPARTMENT OF NUCLEERE MEDICINE ${ }^{4}$

Hashimoto thyroiditis (HT) is the most common cause of hypothyroidism. Subacute thyroiditis (SAT) is an uncommon disease with characteristic clinical features. Coexistence of HT and SAT is very rare and diagnosis can be challenging.

CASE: A 42-year-old woman with HT and multinodular goiter under levothyroxine sodium (LT4) therapy admitted to internal medicine clinic with 1 month history of anterior neck pain radiating to jaw. Thyroid function tests (TFT) were normal, erythrocyte sedimentation rate (ESR) and C-reactive protein (CRP) were mildly elevated. Neck ultrasonography (NUS) revealed a hypovascular focal area in left lobe (LL) which could be consistent with thyroiditis. However, NUS showed an increase in the size of focal area a week later. She was referred to endocrinology clinic for differential diagnosis (DD). Complaints were consistent with SAT, however TFT, ESR and CRP were normal. LT4 was stopped due to the possibility of thyrotoxicosis in SAT and to perform thyroid scintigraphy (TS). She was anxious and had another NUS by her own will 12 days later. NUS reported further progression of area in $\mathrm{LL}$, and formation of a new area in right lobe (RL) with a suspect of thyroid lymphoma (TL). TS revealed decreased LL activity and increased background activity. DD included 3 rare situations: TL, painful HT and SAT co-existing with HT. Clinical presentation was consistent with SAT, however no inflammatory response and thyrotoxicosis developed. TL is more prevalent in HT but rarely painful. However, rapid progression of NUS findings suggested lymphoma possibility. We performed fine needle aspiration biopsy (FNAB) to exclude TL. FNAB demonstrated giant cells compatible with SAT. She refused steroid therapy. During follow up thyrotoxicosis was not observed and thyroid stimulating hormone increased gradually. LT4 was initiated again. At the end of 6 months, NUS findings showed complete regression.

CONCLUSION: HT, an autoimmune disease, can alter the course of SAT and FNAB may be required for differential diagnosis.
Table-1: Laboratory findings

\begin{tabular}{|c|c|c|c|c|c|}
\hline & 19/08/2014 & $30 / 082014$ & $08 / 09 / 2014$ & 23/10/2014 & $06 / 02 / 2015$ \\
\hline ESR (0-20/hour) & & 17 & 24 & 22 & 7 \\
\hline CRP (0-5mg/L) & 30,4 & 10 & 3 & 2,9 & 1,9 \\
\hline $\begin{array}{l}\text { TSH }(0,27- \\
4,2 \mathrm{mIU} / \mathrm{mL})\end{array}$ & 3,2 & 2,54 & 1,4 & 13,3 & 2,2 \\
\hline $\begin{array}{c}\text { Free T4(0.9- } \\
1,70 \mathrm{ng} / \mathrm{dL})\end{array}$ & 1,22 & 1,19 & 1,37 & 1,20 & \\
\hline $\begin{array}{c}\text { Free T3(1,8-4,6 } \\
\text { pg/mL) }\end{array}$ & & 2,76 & 2,63 & 2,57 & \\
\hline NUS & $\begin{array}{l}\text { LL 9,9*11,2 } \\
\text { mm } \\
\text { hypovascular }\end{array}$ & $\begin{array}{c}\text { LL } 17 * 15 * 11 \\
\mathrm{~mm} \\
\text { vascular }\end{array}$ & $\begin{array}{l}\text { LL } 22 * 10 * 15 \mathrm{~mm} \\
\text { hypovascular } \\
\text { RL } 5,5 * 6 * 11 \mathrm{~mm}\end{array}$ & & $\begin{array}{l}\text { Complete } \\
\text { regression }\end{array}$ \\
\hline
\end{tabular}

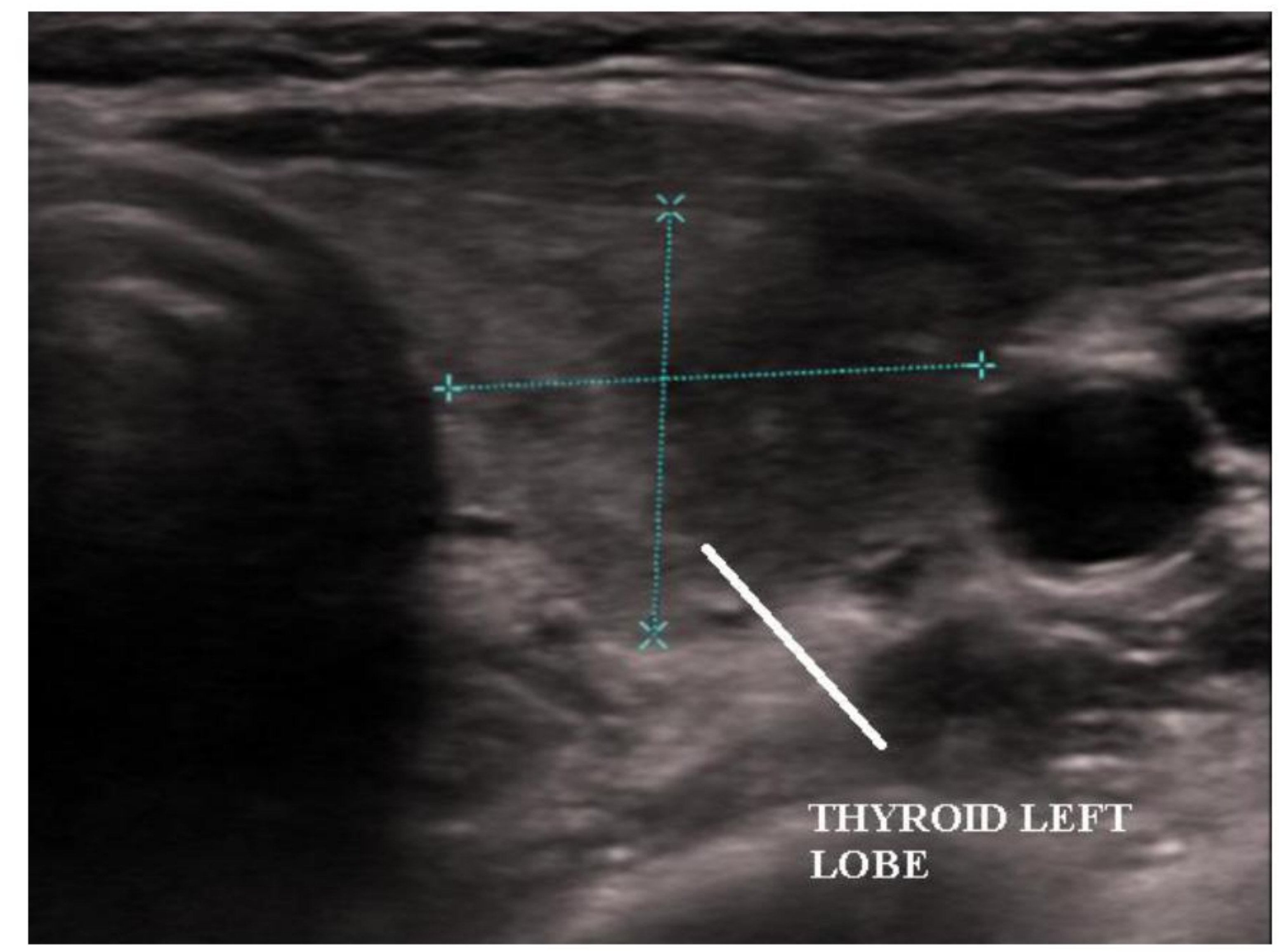

Figure-1: Thyroid ultrasonography (19.08.2014)

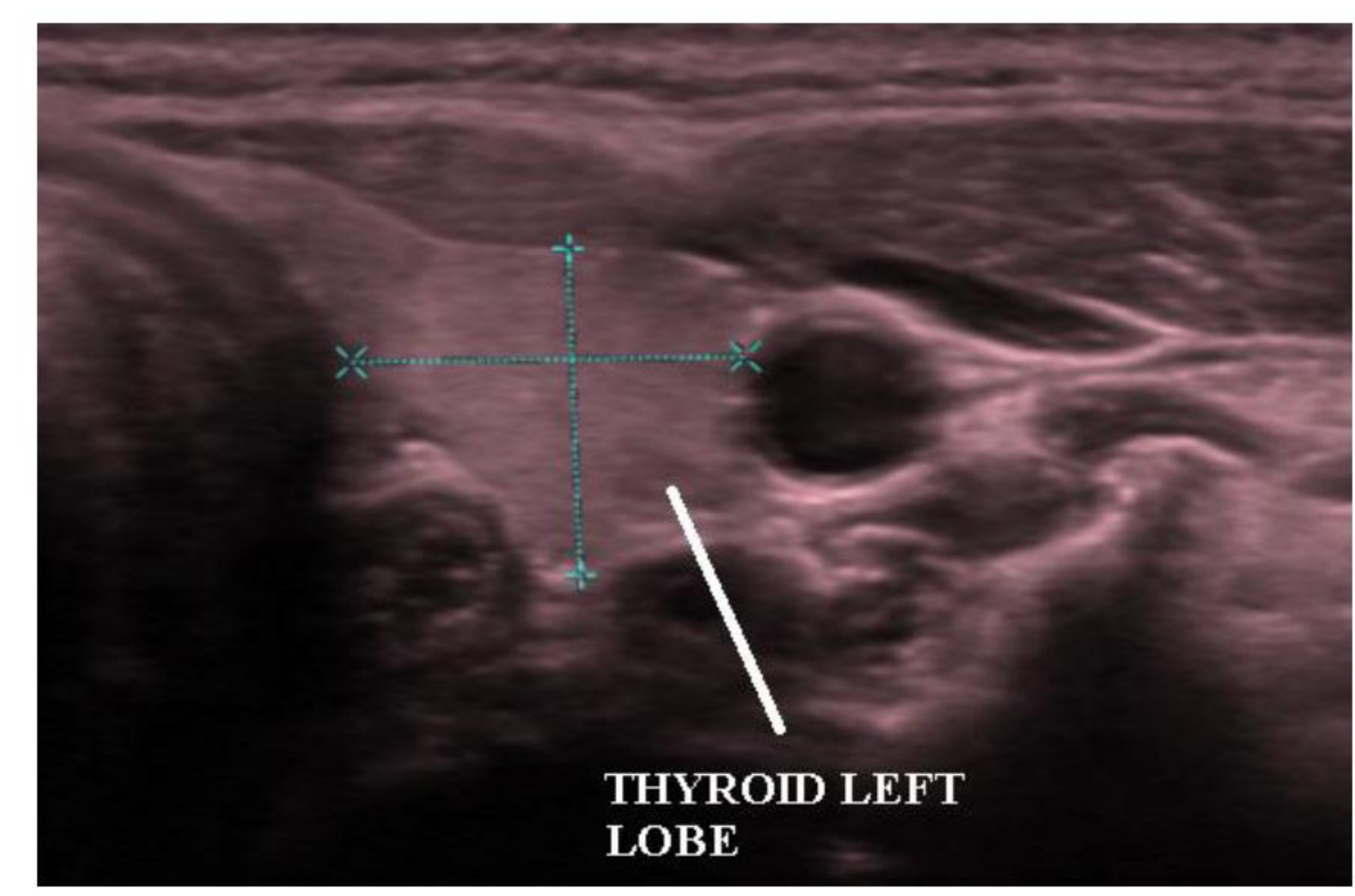

Figure-2: Thyroid ultrasonography (05.02.2015) 